\title{
Chemists without Borders
}

Isis, volume 109, number 3 (2018): 597-607.

\section{Bernadette Bensaude-Vincent, ${ }^{a}$ Université Paris I Panthéon-Sorbonne}

\begin{abstract}
While chemists today work in a variety of professional domains_-ranging from medicine and pharmaceutical companies to nuclear technology, biotechnology, and nanotechnology — students are taught chemistry as if it were a unified discipline with a specific territory and a common language shared by all chemists. The chemists' imaginary is shaped around the image of a diaspora: a scattered population of former inhabitants of a homeland immersed in foreign countries and yet retaining their cultural identity. This essay suggests an alternative perspective on the basis of four different case studies of engagement of chemists beyond the traditional turf of chemistry: nuclear technology, materials science and engineering, synthetic biology, and nanotechnology. Instead of assuming that there is a predetermined territory of chemistry, it argues that the epistemic profile of chemistry is shaped by the various "terrains" (or fields) where chemists are working. The image of a family tree deeply rooted in soil should be replaced by that of a large and loose rhizome network.
\end{abstract}

Students are taught chemistry as if it were a unified discipline with a specific territory and language shared by all chemists. While chemists today work in a variety of professional domains, ranging from medical and pharmaceutical companies to nuclear technology, biotechnology, and nanotechnology, it is tacitly assumed that they still belong to a chemical community. The chemists' imaginary is shaped around the image of a diaspora: a scattered

a Do you prefer not to hyphenate your name? I followed the usage in your biographical footnote and added the hyphen (that's also the way it appeared in your 2016 "Viewpoint" piece), but I will of course conform to your preference here and in the other Focus essays. It's OK with hyphen 
population of former inhabitants of a homeland immersed in foreign countries, and yet retaining their cultural identity. This imagined community regularly materializes for major celebrations or gatherings, such as the semiannual meetings of the American Chemical Society (ACS). While such ritual events undoubtedly reinforce the feeling of belonging to a huge family, they do not necessarily convey the picture of a family tree deeply rooted in soil. Rather, they may suggest the image of a large and loose rhizome network. A chemical tree would grow from a single trunk rooted in fundamentals, with the various limbs of applied chemistry branching out and covering neighboring territories. By contrast, the rhizome metaphor, as described by Gilles Deleuze and Felix Guattari, develops horizontally in a field, with no identifiable origin or end. While the root/tree system charts a hierarchical organization through bifurcations, the rhizome network generates multiplicity. ${ }^{1}$ Which model is more appropriate to capture the identity of contemporary chemists?

To historians of chemistry who span the longue durée, the nostalgic view that there was a period in the past when chemistry had a core territory with a population of practitioners sharing the same language and the same theoretical framework and practical skills is far from persuasive. Over the centuries of so-called modern chemistry, people with chemical skills have been working in a variety of craft, industrial, and agricultural sectors, with no evidence of a shared home to which they all belong. To be sure, chemistry did indeed become an autonomous discipline, with chemistry professorships in many countries and academic diplomas that certify completion of training. ${ }^{2}$ But the existence of a discipline and the emergence of a profession do not imply that chemistry ever had an identifiable territory among the natural sciences.

A territory with identifiable borders that chemists can cross without losing their identities is a misleading image. As chemistry has covered the mineral, plant, and animal realms over the 
centuries, it is difficult to delineate its territory in terms of a specific area within natural phenomena. Chemists tend to define their science in very general terms, such as the study of material substances. But as Linus Pauling rightly noted in College Chemistry, this kind of definition is both too narrow (since chemistry also involves the study of energy) and too broad (since physicists also study material substances, from the nuclei of atoms to celestial bodies, biologists study the substances of living organisms, and geologists the substances that make up the Earth). ${ }^{3}$

Confronted with the difficulty of defining their object of study, chemists often distinguish their science in terms of practice (as the art of analysis and synthesis, in textbooks from the seventeenth to the nineteenth century) or with reference to their aims, which vary greatly — from describing to theorizing, controlling, or using material substances. The common trunk of the various branches of chemistry is limited to the broad theoretical framework presented in chemistry textbooks in higher education of their day. In Thomas Kuhn's terms, it would be hard to identify the shared exemplars, values, and aims that constitute the paradigm of chemistry in a given period. For instance, in 1800 the new language forged by French chemists in 1787 was almost universally accepted, but chemists did not share a core theory. Many of them adopted the new language because it was useful and convenient, without committing themselves to Lavoisier's theory. ${ }^{4}$ The nineteenth century qualifies as a plausible candidate for such a golden age: chemistry was redefined around synthesis, with the assumption that all elements could be identified by their respective atomic weights and valences. However, a closer look at this period suggests that the periodic system did not actually recompose the whole of chemistry and that there was not a core theory that could operate as a central dogma around which a community might coalesce. In 1900 most chemists subscribed to chemical atomism as a "law-like theory" (to 
use Alan Rocke's terminology in his essay in this Focus section), but Marcellin Berthelot and others rejected atomism as a "constructive theory," and some of them—like Wilhelm Ostwald— developed alternative theoretical frameworks, such as energetics.

The image of a territory with delineated borders is nevertheless interesting, because it draws attention to chemists' long-standing concerns with their identity; these concerns have been repeatedly expressed in their controversies with physicists and biologists. At the same time, that myth encourages the view that the chemical territory is disintegrating and that chemistry has become merely a service science, providing toolkits to address problems that are raised by others who are not chemists. Chemistry has become more and more invisible; it is at the same time everywhere and nowhere to be found. The increasing number of Nobel Prizes in Chemistry awarded for achievements in molecular biology or instrumentation may be seen as an attempt to fight the chemists' feeling of injustice at being ignored. ${ }^{5}$

On the basis of a study of four different cases of the engagement of chemists beyond the traditional turf of chemistry - in nuclear technology, materials science and engineering, synthetic biology, and nanotechnology — this essay will suggest an alternative perspective. Instead of assuming that there is a territory of chemistry, I will argue that the epistemic profile of chemistry is shaped by the various "terrains" (fields) where chemists are working. More precisely, the old model of a tree, with its trunk of core basic concepts and branches of applied chemistry, gives way to the model of a technoscience. In order to avoid the postmodernist connotations of this phrase, let us define "technoscience" as characterized by three features: a close interaction between science and technology, with investigative pathways driven by instruments or technological bottlenecks; a specific regime of knowledge production ruled by national or international research policies and characterized by transdisciplinary research fields and 
public/private partnerships; and the incorporation of various heterogeneous values in research motivations - epistemic values explicitly coexisting with military interests, economic competition, and societal and environmental values. ${ }^{6}$

\section{NUCLEAR TECHNOLOGY}

Although most of the credit (and blame) for the success of the Manhattan Project usually goes to physicists, chemists played a key role in the making of the nuclear weapons. ${ }^{7}$ In particular, Glenn Seaborg and Joseph W. Kennedy discovered plutonium-239 and demonstrated that this longerlived isotope was fissionable when bombarded with slow neutrons. In addition, the making of the bombs required a great deal of chemical engineering for the large-scale production of uranium and plutonium. ${ }^{8}$ The DuPont Company signed a contract with the U.S. government on 21 December 1942 to cooperate in the making of the bomb. ${ }^{9}$ DuPont created a new division- the TNX Division - to take charge of the technology and the manufacture of fissile materials. The division built a plant at Hanford, in Washington, with forty-five thousand employees, that began the production of plutonium in the winter of 1943. The company's cooperation with the nuclear program was renewed during the Cold War with another contract signed on 17 October 1950. DuPont engineers contributed to the production of bomb material in the Savannah River, South Carolina, plant, which included five plutonium production reactors, a unit for heavy water production, and two units for PUREX separation. Beyond the war efforts, chemists were engaged in a long-term commitment to work in nuclear technology, instantiated by the leading role of Seaborg as chair of the Atomic Energy Commission from 1961 to 1971.

It is certainly possible to portray the chemists working with the Manhattan Project as providers of solutions for a number of problems raised by the making of the bombs. Not only did 
they [afford the sine qua non condition] $]^{b}$ for the plutonium bomb dropped on Nagasaki, but they also purified uranium nitrate and developed corrosion-resistant coatings for the fissile materials. ${ }^{10}$ In particular, research into isotope separation by gaseous diffusion ran into severe difficulty because the highly corrosive uranium hexafluoride gas damaged the pipes. To seal the pipes, DuPont was able to use polytetrafluoroethylene, which had been invented in 1938 by Roy Plunkett from DuPont and trademarked by the company in 1945 as Teflon. ${ }^{c}$ Moreover, as Pap Ndiaye convincingly argued, DuPont engineers used their experience in scaling up and the logistical skills acquired in the industrial production of nylon for mass-producing fissile materials. They imposed on reluctant physicists the construction of a pilot plant at Oak Ridge, Tennessee, for enriched uranium production.

However, it would be inadequate to think of these chemists metaphorically as émigrés working in a foreign country, because they fully cooperated in the emergence of a new technology. Although DuPont was a simple provider of explosives to the government in World War I, in World War II the company worked in partnership with the state and with academic scientists. Through decades of immersion in the "military-industrial complex" (as Eisenhower called this kind of production system), they not only acquired new technical capacities but also stabilized the new field of nuclear chemistry, which proved to be crucial for the study of chemical and biological reactions as well. This sub-branch of chemistry developed at the interface of chemistry, nuclear physics, biology, and cosmology and is still extremely important in radiation protection studies.

\section{MATERIALS RESEARCH}

b Please clarify: Do you mean that they solved all the problems that enabled production of that bomb? Or-? No I mean they managed to isolate and prepare highly pure plutonium c Should Teflon also get a trademark symbol? Yes you can add it 
Just like nuclear chemistry, materials science instantiates the process of hybridization of disciplines that is a characteristic feature of the technosciences. Departments of materials science and engineering were created in a number of U.S. universities in the early 1960s. This new science of materials grew out of solid-state physics, when X-ray diffraction and, later, electron microscopes provided access to the microstructure of metals. With its focus on structuresensitive properties, solid-state physics is highly theoretical, but it became more practice oriented when new materials with unprecedented properties were needed for nuclear reactors and rockets. Instead of focusing on the relationship between structure and properties, scientists were asked to design materials with specific functions.

It is this predominance of function over structure that led to composite materials: materials made of two or more heterogeneous components, usually a resin and a reinforcing fiber. Whereas traditionally materials such as stone, wood, glass, metals, and plastics were classified according to their physical structure, composite materials are mixtures of different structures. Plastics reinforced with glass fibers were developed in the 1940s for military purposes and later for the automotive industry, while stronger composites with carbon as reinforcing fibers have been commercialized for aircraft and sports equipment. ${ }^{11}$

Composites gradually emerged from polymer chemistry, and in some respects they can be considered as a branch of chemistry. For example, a synthetic aramid fiber named Kevlar ${ }^{\circledR}$ was invented by Stephanie Kwolek in DuPont's laboratories. While working on low-temperature processes for the preparation of condensation polymers, Kwolek realized that she could prepare a liquid crystalline solution in which the molecules all line up pointing in the same direction. The discovery of the fiber commercialized as Kevlar ${ }^{\circledR}$ was not based on the theoretical predictions 
regarding condensation polymers made by Paul Flory. Rather, it developed out of the investigation of a new process of synthesis. ${ }^{12}$

However, composite materials are much more than a branch of chemistry. The practice of reinforcing plastics led chemists to turn their attention toward the interface between two phases. Because the mechanical properties of heterogeneous structures depend on the quality of the interface between the fiber and the polymer, it was crucial to develop additive substances favoring chemical bonds between the glass and the resin. Interfaces and surfaces thus became a prime concern of materials research. A whole new field of research—molecular surface science - aimed at understanding the electrical, magnetic, and optical properties of surfaces on the molecular level thus emerged over the past several ${ }^{\mathrm{d}}$ decades. ${ }^{13}$

Moreover, the Kevlar ${ }^{\circledR}$ case exemplifies the close connection between products and processes in the technology of materials. The interplay between structure, properties, and function is only one aspect of the design of materials. In fact, the design requires a systems approach, taking into account the four variables of structure, property, function, and process. They form the conceptual basis of an interdisciplinary discipline known as materials science and engineering, which emerged in the United States in the 1960s as a result of the strong national policy of funding and equipping interdisciplinary laboratories and departments. ${ }^{14}$

The Materials Research Society (MRS), founded in 1973, holds its annual meeting in Boston; it is attended by thousands of people, just like the semiannual ACS meetings. However, according to one of its members - and again metaphorically—participants are linked to the MRS by weak bonds like ionic bonds, while they retain strong covalent bonds with their core discipline. In Europe the MRS bonds were especially weak, in the absence of strong national

d Okay to insert "several" here? Or-too limited? OK 
incentives for implementing and funding materials research. This does not mean that there was no materials research going on. Quite the contrary; Europe was at the cutting edge in a number of highly competitive sectors. But this kind of research was conducted within the boundaries of the existing disciplinary structures of research agencies. ${ }^{15}$ For instance, an international community of researchers working on fast ion transport in solids emerged in the 1970s, with the aim of designing solid-state batteries for electric vehicles. Fundamental studies and applied research have been conducted on a model material called beta-alumina, which involved chemists looking for high ionic conductivity at ambient temperature and physicists seeking to understand the mechanisms of fast ionic diffusion in solids on a structural and thermodynamic basis. In Europe beta-alumina and other solid ionic conductors were investigated in a subfield of chemistry named solid-state chemistry, whereas they were one of the major foci in materials science and engineering departments in the United States. According to Stanley Whittingham, who completed his Ph.D. in England and then moved to Stanford: "In England, France, and Germany, solid-state chemistry was a respectable subject. Chemistry departments did solid-state chemistry. In the U.S. you could count the number of solid-state chemists on the fingers of one hand. So I went to a materials science department, not to a chemistry department." ${ }^{, 16}$

Biomimetic materials and processes is another booming research field that belongs either to materials science or to chemistry, depending on local and institutional frameworks. Materials chemists attempting to design multifunctional materials and smart structures capable of reacting to their environment were quick to realize that biomaterials could be used as sources of inspiration. In particular, the thin but robust silk of spiders and biominerals like mollusk shells attracted their attention. Materials chemists started collaborating with marine and molecular biologists to study the complex hierarchy of structures of biomaterials with structural features 
occurring on scales of different sizes, from the angstrom scale to the micron and millimeter scales, as well as the processes of self-assembly in biomolecules. "Supramolecular chemistry," promoted by Jean-Marie Lehn in 1978, makes extensive use of hydrogen bonds in an attempt to reproduce the receptor-substrate interaction specificity, which is extremely frequent in biology. Thanks to these forms of molecular recognition and assembly mechanisms, building blocks can self-assemble to form supramolecular structures and even generate macroscopic materials.

To imitate nature's ways of self-assembling components, chemists have developed a new “chemical culture," for which Jacques Livage coined the phrase "chimie douce" (soft chemistry) in $1977 .{ }^{17}$ While conventional synthetic chemistry usually takes place in extreme conditions that are costly in terms of energy, uses large quantities of organic solvents, and produces undesirable waste products, biomimetic chemistry relies on chemical reactions that take place at room temperature in rather "messy" aqueous environments. The development of soft chemistry has led to the use of increasingly complex raw reagents, including macromolecules, aggregates, and colloids. Thus, chemists engaged in materials research are by no means expatriates in a foreign country. Whether they work in a subdiscipline of chemistry or in an interdisciplinary institutional structure, they have been able to open chemistry to new approaches and processes. They are expanding chemistry by growing new rhizomes in novel fields.

\section{SYNTHETIC BIOLOGY}

Designing living organisms, or at least the substances made by living organisms, is an old dream among chemists, propagated by the persistent legend that the synthesis of urea destroyed the metaphysical belief in a vital force. ${ }^{18}$ The chemists' dream is becoming reality in the hands of bioengineers who have set up various programs to design biological systems. When they met in a 
conference in the early 2000s they coined the phrase "synthetic biology." Why should they take chemistry as a model, since their design practices involve reprogramming microorganisms? For the pioneers of the field it was clear that synthetic biology proceeds from the fusion of two worlds: molecular biology, which provided access to the building blocks of life, and computational technologies. Once the code of life was deciphered thanks to genomics, the time had come to rewrite it. The transition from reading to rewriting, from molecular biology to synthetic biology, has been compared with the transition that chemistry underwent in the midnineteenth century from a science focused on analysis to a science aimed at synthesizing new compounds. ${ }^{19}$ The parallel with synthetic chemistry makes sense, in so far as synthetic biologists claim that they will provide safer and cleaner substitutes for chemical products. So the phrase "synthetic biology" appropriately conveys the view that biology is bound to overtake chemistry.

Nevertheless, synthetic biology provides a number of synthetic chemists with a terrain where they can use organic synthesis methods to create artificial molecules capable of behaving like biological entities. ${ }^{20}$ For chemists such as Pier Luigi Luisi and Steve Benner, synthetic biology is much more than engineering bacteria for producing biofuels or medicines. It is an ambitious cognitive enterprise aimed at understanding why nature created life in a certain way. Their basic assumption is that life is a process involving the dynamic interaction of thousands of molecular components. Since there is no teleology in biological evolution, they want to understand why the actual molecules of life came into being, rather than other ones. Why DNA? Why the twenty amino acids for all proteins?

To address such large questions, they do not try to create life ab initio. Rather, they use their synthetic skills to make alternative forms of DNA and enzymes, in order to see whether there are reasons why the existing molecules rather than others have been selected. Albert 
Eschenmoser from ETH Zurich synthesized alternative nucleic acids, replacing ribose with pyranose, in order to disentangle some of the working procedures of biological evolution. Later on Benner, from the University of Florida at Gainesville, noted that the structure of DNA challenged the laws of chemistry because of the sequence of two negative charges in its backbone. He and collaborators consequently made an attempt to "fix God's mistakes." ${ }^{, 21}$ But the synthesis of nonionic DNA backbones was a failure. A more perfect DNA respectful of the laws of electrochemistry would not work. From this failed attempt they conjectured that repeating charges have a role in the function of DNA.

Similarly, some chemists changed the four bases of DNA to make exotic DNAs. Another group synthesized "never-born proteins" in order to show that in some cases artificial enzymes with only ten or twelve amino acids could work. In their attempts to design "life as it could have been," chemists mainly seek to outline the role of contingency and the circumstances that have shaped the actual structure of natural DNA. ${ }^{e}$ However, the [cognitive role of synthesis] ${ }^{\mathrm{f}}$ does not hamper its practical utility. Benner proudly observes that the synthesis of artificial DNA led to branched DNA diagnostic assays. And a number of chemists argue that artificial genetic codes may be needed in case catastrophic climate changes erase life as it now exists from the Earth.

Thus, it is clear that even if synthetic organisms replace chemical refineries in the future, synthetic chemists have found a niche in this booming field. Synthetic biology affords a ground to rejuvenate chemists' ambition to understand the secrets of life and at the same time to develop useful applications. Chemists share the benefits of this fashionable research trend without sharing the research agendas of the champions of synthetic biology. In particular, they peacefully

\footnotetext{
e Should a source (or sources) be cited for the two quotations in this paragraph? Or just general sentiments? It's a general impression f Please clarify: Do you mean that thinking about how to "play" with synthesis (as in the cases you outline above) is no bar to usefulness-and indeed usefulness may arise in unexpected places? You are right: It's exactly what I mean.
} 
coexist with the reductionist BioBricks Foundation program and quietly pursue their own research program under the umbrella of synthetic biology. ${ }^{22}$

\section{NANOTECHNOLOGY}

In the early days of nanotechnology, Eric K. Drexler presented the methods of organic synthesis as dirty, messy, and primitive ways of making things. His depiction was that of chemists haphazardly mixing reactants in a vessel in the hope that a sufficient number of molecules would eventually fall into the right place to make the desired product. By contrast, nanotechnologists would manipulate individual atoms and molecules, piecing them together like Lego ${ }^{\circledR}$ bricks. A bottom-up process would build complex molecular chains cleanly and efficiently in molecular manufacturing facilities. ${ }^{23}$

Not only did Drexler announce the death of chemical industries-just as the champions of biotechnology had done- - but he also challenged chemists on their own turf: molecular science and technology. Unsurprisingly, his claims were followed by an outcry from chemists. In particular, Richard Smalley, co-inventor of fullerenes, humorously responded that chemical reactions rely on the "love relations" between molecules. Other chemists argued that Drexler's bottom-up model miniaturizing ${ }^{\mathrm{g}}$ mechanical engineering was unrealistic, as it failed to acknowledge the special chemistry of the nanoworld. They consequently pointed to more inventive ways of engineering at this scale — for instance, by taking advantage of intermolecular interactions. $^{24}$

Supramolecular chemists actually built up a collection of molecular machines. The 2016 Nobel Prize in Chemistry awarded to James Stoddart, Jean-Pierre Sauvage, and Ben Feringa

g Does “miniaturizing” capture your sense here? It's perfect 
reassessed the chemists' empire over the nanoworld. Both Stoddart and Sauvage insisted that they exclusively used the resources of chemistry—templates and molecular topology in particular - to make catenanes, rotaxanes, switches, and shuttles. ${ }^{25}$

More generally, chemists are deeply involved in the bottom-up construction of molecular machines that integrate all functions in a minimum number of molecules-ideally, a single molecule. For instance, to design a molecular calculator, they have to integrate electronic functions into a molecule, clip the molecule in a given position and conformation on the surface in order to ensure that the functional group is not [removed by the surface, $]^{\mathrm{h}}$ and secure the contact with the nanoelectrodes. Such an agenda requires a complicated multistep synthesis of highly purified polyaromatic molecules on metallic surfaces. The process is assisted by use of a scanning tunneling microscope (STM) and computer techniques to extract the conformation from the visualization. "Chemistry under the tip" (of a STM) is a challenge and a pleasure, said one chemist, "because it gives you an intimate access to the molecule." ${ }^{26}$ Such work requires not only considerable synthetic skills and efforts to increase the yield but also the development of new deposition techniques.

Chemists are not just providing technical support for making molecular machines; they are also advancing their science. If many of them feel at home in nanotechnology, it may be due to their familiarity with carbon, which is the star of nanomaterials. Good old carbon has been investigated over centuries, in various contexts, and yet it continues to offer surprises.

Fullerenes, often considered as the first known nanostructure, were identified by an astrochemist, Harold Kroto, who was interested in the chemistry of clusters of organic molecules

\footnotetext{
h I'm not sure that this is question that can be answered simply, but I'll try: Is it something about the surface itself that would interact with the functional group-thus removing it? (And changing the surface in the process?) Or-? It's the surface reacting with the functional group and changing its properties or functionalities
} 
detected by radiospectroscopy in the cold, dark clouds of interstellar space. Together with Richard Smalley, he utilized mass spectroscopy to conclude that clusters of sixty or seventy atoms of carbon had a Buckminster Fuller-like dome structure. This became a hot topic when Wolfgang Krätschmer, Donald Huffman, and their coworkers prepared a solid C-60 substance and characterized it as a new allotrope of carbon. The publication of the Krätschmer-Huffman method for making fullerenes prompted the electron microscopist Sumio Iijima to embark on a detailed study of similar tubular structures. In examining graphite electrodes used to generate arc discharges he found nanotubes. ${ }^{27}$ These were subsequently easily accessible to everyone, given the simplicity of the technique. His report, published in $1991,{ }^{\mathrm{i}}$ is celebrated as the paper that kicked off nanotechnology.

Strictly speaking, however, nanotubes had been around long before Iijima's discovery, for chemists subsequently realized that they had met them many times before, without identifying them as carbon nanotubes. ${ }^{28}$ There they were in the hair-like carbon filaments used by Thomas Edison and Joseph Swan in their electric lamps. There they were in the "carbon vermicules" that a British ceramic chemist reported as undesirable defects in black-furnace brickworks. The "hollow tube" or "central tube" had even been described in detail in the 1980s by the Japanese material chemist Morinobu Endo, who was investigating "vapor-grown carbon fibers by catalytic decomposition of benzene" as a cheaper alternative to the complex PAN process used to produce the carbon fibers inserted in composite materials. ${ }^{29}$ But their hollow structure elicited no particular interest among materials scientists and engineers who were concerned with industrial production.

Just as nanotubes can be seen as the continuation of the long-standing interest of chemists

i Date okay? Note 27 cites a paper by Iijima and Ishahashi that appeared in 1993. In this case could you please add here the following reference : Iijima Sumio, «Helical microtubules of graphitic carbon», Nature, 354 (1991) p. 56-58. 
in carbon filaments and fibers, graphene, the rising star of nanotechnology that was discovered in 2004, can be seen as a continuation of the long-standing interest of chemists in graphite. In the 1950s graphite became a strategic material for nuclear technology, as it was used to slow the neutrons emitted by the fission of uranium. Chemists then learned to purify it and carefully analyzed its porous structure in order to prevent the damage caused by high temperatures and radiation. ${ }^{30}$ And chemists are still conducting structural studies of graphite, in particular for the decontamination of irradiated nuclear graphite waste and for the detection of hydrocarbons trapped in oil and gas shales. Graphite has also been used in $^{\mathrm{j}}$ the 1980s to make intercalation compounds. Graphene, which is essentially a thin film of graphite, was isolated in the 1960s and named "graphene" (from graphite + benzene) in the 1980s by Hans-Peter Boehm, a chemist and former editor of the journal Carbon. ${ }^{31}$ For carbon chemists it was essentially a theoretical model, a paper tool. But when graphene came back in Manchester in 2004 as "a pure surface," a freestanding monolayer of graphite transferable from one substrate to another, and consequently actionable, it became a wonder material. ${ }^{32}$ Because of its unique combination of propertiesmechanical strength, flexibility, high electrical conductivity, and above all large surface area per unit of mass - it has all sorts of technological applications in biomedicine, communication technology, and composite materials and consequently has attracted heavy investment. In addition to the promise of disruptive technologies, graphene generates fundamental research: from brand to bench, physicists are investigating its electronic behavior and chemists are exploring the prospects of other potential two-dimensional materials such as boron nitride and metals sulfides in order to build up heterostructures layer by layer. Thus graphene chemists are reviving the dream of bottom-up manufacture through nanotechnology.

j Would "since" be better here? Is it still being so used? Yes it is still being used for intercalation compounds. 
To conclude, this survey of four among many fields where chemists have been active over the past decades (one might name pharmaceuticals, the computer industries, or cosmology) suggests that the tree-like model of a fundamental discipline with branches of applied sciences is not adequate. Chemistry grows horizontally, in a rhizomatic fashion. Chemists do not simply intervene to solve the research questions raised by other scientists. They co-construct technoscientific fields and open up new avenues of research. For instance, the emerging field of "Anthropocene" studies was initiated by the atmospheric chemist Paul Crutzen, who coined the term to refer to the era when humans became a geological force. ${ }^{33}$ Here again, a new avenue of research on the Earth system opened up, co-constructed by chemists, geologists, climate scientists, and social scientists.
\end{abstract}

If the site of chemistry is the interface between human actions and material agencies, the identity of chemists cannot be defined by the territory of their investigations. It rather proceeds from their style of thinking. Not only do they bring natural substances into the laboratory to purify and analyze them, but they are also learning and knowing through making. As exemplified in the fields surveyed in this essay, chemists are designing new materials. "Chemistry creates its object": the creativity that Marcellin Berthelot first identified as the distinctive feature of chemistry has been so amplified during the past century that chemistry may well have turned the entire Earth into a laboratory, a world laboratory. ${ }^{34}$ 
Bernadette Bensaude-Vincent, Professor Emeritus at Université Paris I Panthéon-Sorbonne, is a philosopher and historian of science. Her research topics span from the history and philosophy of chemistry to materials science and nanotechnology. Her publications include History of Chemistry (1997) ; Chemistry: The Impure Science, with Jonathan Simon (Imperial College, 2008); Fabriquer la vie: Où va la biologie de synthèse (Seuil, 2011)'; and Research Objects in Their Technological Settings, edited with Sacha Loeve, Alfred Nordmann, and Astrid Schwarz (Routledge, 2017). Département de Philosophie, Université Paris 1 Panthéon-Sorbonne, 17 Rue de la Sorbonne, 75231 Paris Cedex 05, France; bvincent@univ-paris1.fr.

${ }^{1}$ Gilles Deleuze and Felix Guattari, A Thousand Plateaus (Minneapolis: Univ. Minnesota Press, 1987), pp. 5-7.

${ }^{2}$ Colin Russell, N. G. Coley, and Gerrylynn K. Roberts, Chemistry as a Profession: The Origins and Rise of the Royal Institute of Chemistry (Milton Keynes: Open Univ. Press, 1977); Mary Jo Nye, Before Big Science: The Pursuit of Modern Chemistry and Physics, 1800-1940 (New York: Twayne, 1996); David Knight and Helge Kragh, eds., The Making of the Chemist: The Social History of Chemistry in Europe, 1789-1914 (Cambridge: Cambridge Univ. Press, 1998); and Ernst Homburg, Anthony S. Travis, and Harm G. Schröter, eds., The Chemical Industry in Europe, 1850-1914: Industrial Growth, Pollution, and Professionalization (Dordrecht: Kluwer Academic, 1998).

${ }^{3}$ Linus Pauling, College Chemistry (San Francisco: Freeman, 1950), p. 5. In the second edition ${ }^{\mathrm{m}}$ of this famous textbook, Pauling changed the definition provided in this introductory section. He

\footnotetext{
k Is this the volume coauthored with Isabelle Stengers that is cited in note 5? (The publication date given there is 1996.) Or-? Yes it is co-authored with Stengers and it first came out in 1996 ${ }^{1}$ Is this a coauthored volume? Co-authored with Dorothée Benoit-Browayes $\mathrm{m}$ Please check; the quotation that follows is attributed to the third edition. Please change for in the subsequent editions
} 
emphasized the difficulty of defining matter and materials and concluded: "Often in science it is necessary to begin with some undefined words" (College Chemistry, 3rd ed., p. 6).

${ }^{4}$ Bernadette Bensaude-Vincent and Ferdinando Abbri, eds., Lavoisier in European Context: Negotiating a New Language for Chemistry (Cambridge, Mass.: Science History, 1995).

${ }^{5}$ Over the past fifteen years (from 2002 to 2017), seven ${ }^{\mathrm{n}}$ Nobel Prizes in chemistry rewarded achievements in molecular biology $(2002,2004,2006,2008,2009,2015)$, and two recognized work in instrumentation (2014 and 2017). For a work that addresses chemists' longtime concerns with their identity ${ }^{\circ}$ see Bernadette Bensaude-Vincent and Isabelle Stengers, A History of Chemistry (Cambridge, Mass.: Harvard Univ. Press, 1996).

${ }^{6}$ Javier Echevarria, La revolución tecnocientífica (Madrid: Fondo de Cultura Económica de España, 2003); David F. Channel, A History of Technoscience: Erasing the Boundaries between Science and Technology (Abingdon: Routledge, 2017); Gilbert Hottois, “Technoscience: From the Origin of the Word to Its Current Issues," in French Philosophy of Technology: Classical Readings and Contemporary Approaches, ed. Sacha Loeve, Xavier Guchet, and Bernadette Bensaude-Vincent (Cham: Springer, in press ${ }^{\mathrm{p}}$ ); and Bensaude-Vincent and Loeve, "Toward a Philosophy of Technoscience," ibid.

${ }^{7}$ Rebecca Press Schwartz, "The Making of the History of the Atomic Bomb: Henry Dewolf Smyth and the Historiography of the Manhattan Project" (Ph.D. diss., Princeton Univ., 2008). ${ }^{8}$ Although chemical engineering is considered as quite distinct from chemistry in certain national contexts, it was a key actor in the development of chemical factories such as DuPont in the twentieth century. As such it is an integral part of chemistry as a technoscience.

\footnotetext{
${ }^{n}$ Number okay? There are only six years given in the next line. OK change for six, please. o "Introduction" to this part of the note okay thus? Please modify it as necessary.

$\mathrm{p}$ Has this volume been published yet? If so, please supply inclusive pages for the two essays from it you've cited here. Yes it has been published in 2018. The pages for Hottois's paper are p. 121-138. And for Bensaude-Vincent and Loeve p. 169-186.
} 
${ }^{9}$ Pap A. Ndiaye, DuPont and the March of Modern America (Baltimore: Johns Hopkins Univ. Press, 2006). As DuPont was initially reluctant to enter into the war effort for fear of being again branded a "merchant of death," the contract specified that its cooperation was a nonprofit arrangement, the remuneration for which included only the reimbursement of expenses and a symbolic \$1 per year.

${ }^{10}$ Stu Borman, "Chemists Reminisce on Fiftieth Anniversary of the Atomic Bomb," Chemical and Engineering News, 17 July 1995, http://pubs.acs.org/cen/hotarticles/cenear/950717/art02.html.

${ }^{11}$ Bryan Parkyn, "Fibre Reinforced Composites," in The Development of Plastics, ed. Susan T. I. Mossman and Peter J. T. Morris (London: Science Museum, 1994), pp. 105-114.

${ }^{12}$ Oral history interview with [Stephanie Kwolek Parc 21, 1998, ]

http://www.worldcat.org/title/oral-history-interview-with-stephanie-1-kwolek-1998-march21/oclc/316216702.

${ }^{13}$ For a review of this field in 1997 see Gabor A. Somojai, "From Surface Materials to Surface Technologies," MRS Bulletin, 1998, 23(5):11-29.

${ }^{14}$ Bernadette Bensaude-Vincent, "The Construction of a Discipline: Materials Science in the U.S.A.," Historical Studies in the Physical and Biological Sciences, 2001, 31:223-248.

${ }^{15}$ Arne Hessenbruch and Bernadette Bensaude-Vincent, interview of Mike Driver, 10 Apr. 2003. ${ }^{\mathrm{r}}$ For the French case see Emanuel Bertrand and Bensaude-Vincent, "Materials Research in France: A Short-Lived National Initiative (1982-1994),” Minerva, 2011, 49:191-214.

\footnotetext{
q Several questions here: Who conducted the interview? I conducted the interview And is Parc part of Kwolek's name? You can delete Parc. Or something else? Is the date 21 March 1998? It's the date of interview.

$\mathrm{r}$ Is there a site where this interview may be accessed-as in the case of the Whittington interview cited in note 16 ? Unfortunately not. You can just mention 'oral communication' to ...
} 
${ }^{16}$ Arne Hessenbruch and Bernadette Bensaude Vincent, interview of Stanley Whittingham, 30 Oct. 2000, https://www.sho.espci.fr. See also Pierre Teissier, "Solid-State Chemistry in France: Structure and Dynamics of a Scientific Community since World War II," Historical Studies in the Natural Sciences, 2010, 40:225-258.

17 The phrase was introduced in Jacques Livage, "Vers une chimie écologique: Quand l'air et l'eau remplacent le pétrole," Le Monde, 26 Oct. 1977.

${ }^{18}$ John J. Brooke, “Wöhler's Urea and Its Vital Force-A Verdict from the Chemists," Ambix, 1968, 15:84-114; and Peter J. Ramberg, "The Death of Vitalism and the Birth of Organic Chemistry: Wöhler's Urea Synthesis in Textbooks of Organic Chemistry,” ibid., 2000, 47:170195.

${ }^{19}$ On the fusion of two worlds see Robert Carlson, Biology Is Technology: The Promise, Peril, and New Business of Engineering Life (Cambridge, Mass.: Harvard Univ. Press, 2010), p 6. For a historical perspective see Brian J. Yeh and Wendell A. Lim, "Synthetic Biology: Lessons from the History of Synthetic Organic Chemistry," Nature Chemical Biology, 2007, 3:521-525; and Bernadette Bensaude-Vincent, "Synthetic Biology as a Replica of Synthetic Chemistry? Uses and Misuses of History," Biological Theory, 2000, 4:314-318.

${ }^{20}$ Pier Luigi Luisi and Cristiano Charabelli, eds., Chemical Synthetic Biology (New York: Wiley, 2011).

${ }^{21}$ Albert Eschenmoser, "Searching for Nucleic Acid Alternatives," in Chemical Synthetic Biology, ed. Luisi and Charabelli, pp. 7-45; and Steve A. Benner, “Redesign DNA: Fixing God's Mistakes," Capstone Lecture, Pittcon Program 2012 Conference, 14 Mar. 2012, http://www.pittcon.org/technical/capstone.php. 
${ }^{22}$ See http://parts.igem.org/BioBrick_Part_Program; and Bernadette Bensaude-Vincent, "Between the Possible and the Actual: Philosophical Perspectives on the Design of Synthetic Organisms," Futures, 2013, 48:23-31.

${ }^{23}$ Eric Drexler, "Introduction to Nanotechnology,", in Prospects in Nanotechnology:

Proceedings of the First General Conference on Nanotechnology, ed. Markus Krummenacker and James Lewis (New York: Wiley, 1995), p. 2.

${ }^{24}$ Richard Smalley, “Of Chemistry, Love, and Nanobots,” Scientific American, 2001, 285(3):76-

77; George M. Whitesides, “The Once and Future Nanomachine,” ibid., pp. 78-83; Richard Jones, Soft Machines (Oxford: Oxford Univ. Press, 2004); and Philip Ball, "Natural Strategies for the Molecular Engineer," Nanotechnology, 2002, 13:15-28.

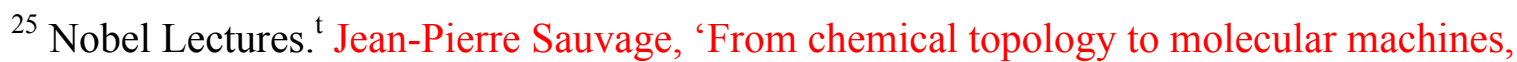
December 8, 2016. Nobel Lectures, p. 111-137. James F. Soddart, "Mechanically interlocked molecules (MIMs)-Molecular shuttles, switches, and machines”. December 8, 2016. Nobel Lectures, p. 179-215.

${ }^{26}$ André Gourdon, from CEMES, Toulouse, interview by Xavier Guchet and Sacha Loeve 10 Feb. 2005. ${ }^{\mathrm{u}}$

${ }^{27}$ Harold W. Kroto, J. R. Heath, S. C. O’Brien, R. F. Curl, and Richard E. Smalley, “C60: Buckminsterfullerene,” Nature, 1985, 318:162; Wolfgang Krätschmer, L. D. Lamb, K. Fostiropoulos, D. R. Huffman, R., "Solid C60: A New Form of Carbon,” ibid., 1990, 347:354358; and Sumio Iijima and T. Ishahashi, "Single-Shell Carbon Nanotubes of $1 \mathrm{~nm}$ Diameter," ibid., 1993, 363:603.

s Please supply inclusive page numbers for this essay.

${ }^{t}$ Please supply more specific information, along the lines of note 32 . See above u Who conducted this interview? And can you supply a link to it? interview by Xavier Guchet and Sacha Loeve 10 Feb. 2005. Unfortunately it's not on-line.

v Is a last name missing here? No just delete R. 
${ }^{28}$ Sacha Loeve, "Point and Line to Plane: The Ontography of Carbon Nanomaterials," in From Bench to Brand and Back: The Co-Shaping of Materials and Chemists in the Twentieth Century, ed. P. Teissier, C. Mody, and B. van Tiggelen (Nantes: Cahiers François Viète, 2017), pp. 183216.

${ }^{29}$ W. R. Davis, R. J. Slawson, and G. R. Rigby, “An Unusual Form of Carbon,” Nature, 1953, 171:756; Morinobu Endo, “Gas Phase Method of Manufacturing Carbon Fibers,” Patent WO 1986004937 A1, 1986; "Grown Carbon Fibers in the Vapor Phase,"w Chemtech, 1988, 18:568576; and Bernadette Bensaude-Vincent, interview with Morinobu Endo, Nagano, 26 Oct. 2002, https://www.sho.espci.fr.

${ }^{30}$ P. L. Walker, Jr., “Carbon—An Old but New Material,” American Scientist, 1962, 50:259_ 293.

${ }^{31}$ Hans-Peter Boehm, A. Clauss, G. Fischer, and U. Hofmann, Surface Properties of Extremely Thin Graphite Lamellae: Proceedings of the Fifth Conference on Carbon (London: Pergamon, 1963), pp. 73-80; and Boehm, R. Setton, and E. Stumpp, "Nomenclature and Terminology of Graphite Intercalation Compounds," Carbon, 1986, 24:241-245.

${ }^{32}$ Konstantin Novoselov, Andre Geim, S. Morozov, D. Jiang, Y. Zhang, S. V. Dubonos, I. V. Grigorieva, and A. A. Firsov, "Electric Field Effect in Atomically Thin Carbon Films," Science, 2004, 306: 666-669; and Novoselov, “Graphene: Materials in the Flatland,” Nobel Lecture, 2 Dec. 2010, https://www.nobelprize.org/nobel_prizes/physics/laureates/2010/novoselov_lecture.pdf.

- $\quad{ }^{\text {w }}$ Should an author be given for this essay? It's M. Endo, Y. A. Kim, T. Matusita, T. Hayashi 
${ }^{33}$ Paul Crutzen and Eugene F. Stoermer, "The 'Anthropocene,"” Global Change: Newsletter, 2000, no. 4, pp. 17-18; and Helmuth Trischler, ed., "Anthropocene: Exploring the Future of the Age of Humans," RCC Perspectives, 2013, no. 3, doi.org/10.5282/rcc/5603.

${ }^{34}$ Bernadette Bensaude-Vincent, "The Chemists' Style of Thinking," Berichte zur

Wissenschaftsgeschichte, 2009, 32:1-14; and Marcellin Berthelot, Chimie organique fondée sur la synthèse, 2 vols., Vol. 2 (Paris: Mallet-Bachelier, 1860), p. 811. 